\title{
Documentología e investigación científica: reflexiones sobre una relación recíproca
}

\section{Francisco Javier García Marco}

En este número monográfico de Scire se recogen una serie de trabajos que tienen como trasfondo las relaciones entre Investigación Científica y Documentología, relaciones que transcurren con fluidez en ambas direcciones y que son de una gran importancia para ambas.

Por un lado, porque la Documentología —o Ciencias de la Documentación, si se prefiere utilizar una denominación más "confederal"- hace mucho tiempo que se postula como ciencia. Ciencia teórica en cuanto que estudia los procesos informativo-documentales en la sociedad, los grupos y los individuos tal y como acontecen en la realidad; y, por supuesto, ciencia aplicada, pues pretende descubrir mejores prácticas y proponer principios y modelos orientados a la acción que, en definitiva, han de servir para optimizar los procesos informativo-documentales que estudia la vertiente teórica de la disciplina.

De dicha afiliación se deriva que la Documentación, en cuanto que ciencia teórica, se sustenta sobre los principios de la Ciencia y de la investigación científica, entre los que cabe destacar los de relevancia, intersubjetividad, sistematicidad, creatividad, simplicidad, precisión, rigor lógico y perfectibilidad. Por otra parte, en cuanto que ciencia aplicada dicha relación de afiliación se concreta más, apoyándose en el binomio investigación-acción — controlado lógicamente por los principios de la ciencia y del método científico — como forma privilegiada de relación entre teoría y realidad.

Si nos trasladamos a la perspectiva recíproca, reconoceremos, por otra parte, que la Documentología como disciplina y actividad práctica constituye una de las principales "ancillae" del método científico, a lo largo del cual resulta prácticamente omnipresente. En primer lugar, porque durante todo el proceso de investigación científica la documentología — en sus diversas especialidades- coadyuva al proceso de adquisición de conocimiento, permitiendo localizar y organizar las fuentes de información externas —ámbito de actividad que tradicionalmente 
se ha venido denominando "Documentación Científica". Efectivamente, gracias a la Documentación Científica es posible realizar dinámicamente y con garantías de calidad el estado de la cuestión que debe enmarcar los objetivos de la investigación y la metodología escogida. Se hace así posible el abordaje del nuevo proyecto dentro de la tradición científica previa, y en definitiva, se consigue asegurar el carácter eminentemente acumulativo de la actividad científica —al menos en el estadio de "ciencia normal" - , toda vez que también la crítica requiere la consideración atenta de la tradición anterior.

Pero la actividad documental no se limita a facilitar el acceso a la memoria documental de la actividad científica anterior, a las "fuentes de información". Antes bien, se sitúa también en el otro extremo del camino de la investigación científica en cuanto que actividad comunicativa, inserta en una tradición, en una comunidad de investigadores y al servicio de la sociedad. Ciertamente, al final del proceso, la Documentología quiere y puede ayudar también en la codificación, difusión y recuperación adecuada de los resultados de la investigación, asegurando el éxito en el proceso de transferencia del conocimiento. Queda soldado así el otro extremo de ese eslabón que cada investigación científica concreta añade a la cadena del progreso de la Ciencia.

Finalmente, la Documentología facilita durante todo el proceso de la investigación científica la gestión de la información y la documentación interna del proyecto. Aunque esta actividad ha sido realizada tradicionalmente por los propios científicos, a medida que los equipos de investigación crecen y la actividad científica se institucionaliza y se organiza en redes de trabajo amplias y cohesivas, requiere cada vez más la concurrencia de profesionales especializados.

Así pues, la relación que existe entre la Documentología y su actividad de referencia, la Ciencia, es quizá más estrecha que la que se produce en el caso de otras ciencias específicas, puesto que en nuestro caso se produce en ambas direcciones. Es cierto que, por parte de los "documentólogos" queda mucho trabajo pendiente por hacer en aras de la calidad, la eficacia y la eficiencia del tránsito en ambos sentidos de ese camino conjunto, pero en este preciso momento deseamos dedicar estas páginas a motivarnos con lo apasionante del reto, dejando coyunturalmente de lado lo perfectible de la tarea; perfectibilidad que, por otra parte y en definitiva, constituye una de las características específicas del saber científico.

Desgraciadamente, en el transcurso del periodo de edición de este número falleció uno de los hijos de nuestro compañero Plácido Díez, uno de los autores del presente volumen. Queremos dedicarle nuestro trabajo, testimoniando a toda la familia nuestra profunda condolencia. 